\title{
A (Des) Verticalização de São Paulo e o Plano Diretor da Cidade
}

\author{
Nadia Somekh
}

Este artigo baseado na pesquisa sobre a verticalização de São Paulo aponta algumas transformaçōes significativas no processo de produçāo do espaço da cidade. Fundamentalmente a análise do crescimento vertical de Sāo Paulo desassocia verticalizaçāo de adensamento, bem como aponta a açāo do Estado interferindo no processo no sentido de limitar significativamente as densidades. Constata-se que São Paulo é vertical, porém não é densa e, que a legislaçāo urbanística foi reduzindo historicamente a oferta de áreas edificáveis. Isto se constituiu um fator de inflacionamento considerável dos preços fundiários, cujo efeito direto é a exclusão dos segmentos de mais baixa-renda do acesso à terra urbana. As constataçōes da pesquisa, principalmente no que diz respeito á possivel reversão de alguns efeitos perversos da aplicação da legislação de zoneamento, foram utilizadas na concepçāo e formulaçāo das propostas no Plano Diretor de São Paulo, apresentado à Câmara em 1991. \footnotetext{
This paper based on a research into São Paulo verticalization points to a number of changes of urban production processo. The analysis dissociates vertical growth from densification and shows how state intervention imposes limitations on density to a significant extent. Indeed São Paulo is highrise but not dense. The urban legislation has progressively reduced land available for urbanization. This induced a sizeble increase in Land prices excludisg thereby the lower income population from legal access to land. The findings of the research, especially those refering to the negative effects of zoning by laws and the eventual elimination of the latter, were included in the proposals of the Master Plan of the City.
}

Artigo elaborado com base na Dissertaçáo de Mestrado "A (des)verticalizaçáo de Sáo Paulo", apresentada em 1987.

Orientadora: Profe Dra Maria Adélia Aparecida de Souza. 


\section{Introdução}

A pesquisa sobre o processo de verticalização da cidade de São Paulo começou em 1978 no âmbito da revisão do Plano Diretor (1971). Era necessário conhecer as áreas de crescimento vertical e a sua dinâmica, para eventualmente controlá-las. Era importante também uma avaliação dos efeitos da Lei de Zoneamento (1972) sobre a cidade.

Uma parte da pesquisa sobre a verticalização de São Paulo ${ }^{1}$ ficou pronta em 1987 e constitui-se numa das fontes para elaboração do Plano Diretor em 1991. Foi importante ter constatado que São Paulo é uma cidade aparentemente densa: a cidade é vertical, mas suas áreas verticalizadas não sāo as mais densas. A explicação para esse fenômeno é que a Legislaçăo Urbanística veio reduzindo ao longo do tempo os coeficientes de aproveitamento permitidos. A redução da possibilidade de verticalizar ampliou a demanda por terra edificável inflacionando os preços fundiários e agravando os problemas de assentamento da população de mais baixa renda. Nesse sentido o Plano Diretor de 1991 propõe uma revisāo dessa tendência histórica, através da ampliação da oferta de terra edificável.

São Paulo é, portanto, uma cidade vertical, mas irracional do ponto de vista da sua densidade de ocupação. Se compararmos o coeficiente de aproveitamento de uma Z5, isto $e^{\prime}$ da zona mais central e mais densa da cidade, verificaremos que seu coeficiente de aproveitamento médio de 3,8 vezes a área do terreno é muito pouco maior que o coeficiente médio de Paris do séc. XIX (sem elevador), que corresponde a 3,5 vezes a área do lote. É interessante notar que sem as possibilidades da tecnologia atual, isto $e_{\text {, }}$ das grandes estruturas e do elevador, uma cidade construlda no século passado apresente niveis de ocupação médios equivalentes à área mais central e mais densa de São Paulo.

Se de outro lado compararmos Paris com São Paulo, verificaremos que São Paulo é muito mais congestionada do que Paris, o que se explica facilmente pela qualidade e pelas especificidades dos sistemas viários e de transportes de cada uma. Se para a primeira o básico é o transporte coletivo de massa, para a segunda historicamente se privilegiou o transporte individual e o ônibus.

A fim de analisarmos as transformaçōes do fenômeno no tempo, definimos verticalização como sendo a multiplicação do solo urbano possibilitada pelo elevador. Abaixo, analisaremos como ocorreu essa verticalização.

\section{O Primeiro Período: A Influência Européia - 1920/1940}

É diffcil precisar o infcio da verticalização em São Paulo. Nesse sentido, e retomando nossa definição do fenômeno que considera o elevador como elemento importante no processo de verticalização, verificamos que seu uso começa na primeira década do séc. XX. Em 1920, na Lei n. 22,332, os elevadores são mencionados prescrevendo-se que a sua existência não elimina a necessidade de escadas.

Em 1925, já atingem um número considerável, a ponto de o Poder Público exigir, pela Lei $n .2,818$, de 09 de fevereiro desse ano, uma licença para o seu funcionamento. Todavia, essa lei só é efetivamente implementada em 1940, quando é criado o registro de elevadores, perlodo a partir do qual a verticalização passa a alcançar número significativo. Nessa época, os elevadores utilizados nos novos ediffcios altos eram todos importados, passando a ser fabricados aqui por volta de 1943 pelas indústrias Villares.

(1) A (des)verticalização de Såo Paulo: dissertação de mestrado de Nadia Somekh - FAUUSP, 1987.

Até 1940, a cidade de São Paulo contava com 1.232 elevadores instalados em 813 edificios. A verticalização era um fenômeno tipicamente central e predominantemente de escritórios; $70 \%$ dos ediff́cios estavam localizados no centro e $30 \%$ em bairros próximos, 
do total de ediffcios $65 \%$ eram de uso terciário. O surgimento da verticalizaçāo na década de 20, estava diretamente associado ao aparecimento de ediffcios comerciais, sendo que os ediffcios residenciais surgem um pouco mais tarde.

Nesse perlodo, a legislação estimulava a verticalização em determinadas áreas fora da área central, por meio do estabelecimento de alturas máximas para os ediffcios, muito superiores àquelas construldas na época. Apesar de o discurso do código de obras de 1929 parecer restritivo do ponto de vista da verticalização, ele a incentivava. No centro novo, a altura máxima era de $50 \mathrm{~m}$ e em qualquer outra via pública (fora da área central) a "altura máxima permitida" era de $80 \mathrm{~m}$. Oitenta metros ou aproximadamente 25 andares, na década de 30, não representava qualquer tipo de restrição, uma vez que até hoje poucos săo os ediff́cios construldos nessas dimensões.

Os coeficientes de aproveitamento, na época, eram grandes: como as construçōes alcançavam o alinhamento das ruas e ocupavam o espaço quase sem recuos ou pátios internos, esse indice era praticamente coincidente com o número de pavimentos, variando de seis (centro velho) a dez andares (centro novo). Alguns "arranha-céus", como o Sampaio Moreira, construldo em 1924, têm o coeficiente de aproveitamento igual a 12 e o famoso Martinelli, de 1929, alcança um C. A. aproximado de 22 vezes a área do terreno.

O Poder Público começa a se preparar para investir efetivamente no sistema viário. O Plano de Avenidas, idealizado por Prestes Maia, começa a ser implantado. A implantação do "Perimetro de Irradiação", conjunto de avenidas em volta do centro, envolvia a área, congestionada, provocando sua expansão. À medida que as obras lam sendo implantadas, a área construlda crescia maciçamente no sentido vertical.

O sistema de bondes gerou um padrāo de urbanização bastante denso. Até 1940, os automóveis eram poucos e importados e os transportes deficientes. Tornava-se necessária, entāo, a proximidade da populaçāo aos locais de trabalho, de comércio e serviços, o que condicionou a verticalização residencial nos bairros lindeiros ao centro, o que iria se intensificar no perlodo seguinte.

\section{O Segundo Período: A Influência Americana - 1940/1957}

Esse perlodo caracteriza-se por uma verticalização predominantemente residencial. 0 crescimento vertical localiza-se nos bairros próximos ao centro, onde os ediffcios já perderam seu aspecto europeu e começam a adquirir, em função da valorização dos terrenos, uma fisionomia norte-americana, caracterizada pela "febre dos arranha-céus". (Muller in Azevedo, 1954, p. 151)

Em 1957, a cidade de Săo Paulo contava com 5.910 elevadores instalados em 3.533 ediffcios, dos quais 2.720 foram construidos entre 1940 e 1957, com a seguinte distribuição: $29 \%$ localizados no centro e o restante em 19 outros bairros, invertendo a situação do perlodo anterior, quando $70 \%$ dos ediffcios estavam no centro e os demais distribuidos por seus outros bairros.

No entanto, a fisionomia americanizada da cidade não pode ser atribulda somente à "febre dos arranha-céus" que surge devido aos altos preços do solo urbano. Os ediffcios de São Paulo eram parecidos formalmente com os dos Estados Unidos, mas tinham uma escala menor. Os "arranha-céus" de Chicago e Nova York atingiam, em épocas anteriores, alturas e coeficientes de aproveitamento significativamente maiores que os de São Paulo. Além disso, os ediff́cios americanos não apresentavam a caracteristica tão peculiar aos ediff́cios paulistas da época: o revestimento de pastilhas. 
$\mathrm{Na}$ área central, a ocupação do solo urbano era praticamente total, sendo livres apenas as áreas internas dos grandes prédios. A existência de um terreno desocupado, em geral servindo de estacionamento, indicava que mais um "arranha-céu" estava para surgir. O mesmo fato repetia-se em proporçōes menores no "Centro Novo", recentemente integrado ao núcleo antigo.

O aproveitamento dos terrenos era intenso em relação aos coeficientes médios do perlodo anterior. Essa ocupação, que pode ser ainda mais significativa se considerarmos a concentração dos prédios mais altos na área central da cidade, indicaria, como aponta Muller (Azevedo, 1954, p. 150), que a área ocupada deve ser multiplicada por 10 , uma vez que "tal cifra pode ser considerada como representativa da média dos pavimentos dos prédios centrais"

Nos bairros, a ocupação do solo para ediffcios é crescente. Por volta de 1950, o crescimento vertical já é visível, em blocos, nos bairros não só próximos ao centro (Vila Buarque e Santa Cecllia) como em bairros mais afastados, como acontece na avenida Paulista e vizinhanças (Muller in Azevedo, 1954, p. 125). O crescimento vertical desse perlodo se expande como um bloco em torno da área central. $A$ baixa acessibilidade da área central, determinada pela constante crise nos transportes, aliada ao aumento dos preços fundiários, provoca uma densa ocupação em torno do centro, nos bairros mais próximos.

A legislação de inquilinato, que congelou temporariamente os aluguéis, provoca uma mudança nas condições da propriedade em relação ao perlodo anterior. Se antes os escritórios e os apartamentos eram alugados, começam nesse perlodo a se tornarem próprios, viabilizados pelos financiamentos das Caixas Econômicas e pelos investimentos dos Institutos de Previdência. A verticalização nesse perlodo apresenta um movimento crescente. A ameaça dos urbanistas de limitar os coeficientes de aproveitamento provocou uma corrida de aprovação de novos projetos.

São característicos desse perfodo os ediff́cios de kitchinettes que foram invibializados pela legislação municipal do perlodo posterior. Esse tipo de apartamento possibilitava, por ser pequeno, a apropriação de uma classe de mais baixa renda, de uma localização mais central, o que mais tarde foi impedido.

\section{O Terceiro Período: A Influência do Automóvel - 1957/1967}

Em 1967, São Paulo contava com aproximadamente 10.900 elevadores instalados em 6.034 ediffcios, dos quais 2.501 foram construldos durante esse período. Em 1957, pela primeira vez em São Paulo, o coeficiente passa a ser limitado para 4 em ediffcios residenciais e 6 para ediffcios comerciais. A Lei n. 5.261, que fixava os C. A., também determinou uma cota mínima de terreno por unidade. Isso definiu o tamanho dos apartamentos desse periodo em $140 \mathrm{~m}^{2}$ para um C. $A_{0}=4$ e $210 \mathrm{~m}^{2}$ para um C. $A_{0}=6$.

Como os construtores da época utilizavam-se do expediente de aprovar ediffcios residenciais como sendo comerciais, a maioria conseguia elevar o C. A. permitindo até 6 . Como resultado, a maioria dos apartamentos construldos entre 1957 e 1967 tinha uma área mínima de $210 \mathrm{~m}^{2}$. Isso selecionou a população que poderia morar em ediffcios de apartamento, isto é, somente quem podia pagar a quantidade área desses ediffcios.

É interessante notar, nos jornais da época, que ao anunciar a Lei n. 3.261, o prefeito "aproveitou" para comunicar a desistência da construção do metrô de São Paulo. Como em 1956 era implantada a indústria automobillstica no Brasil e em São Paulo, observamos a existência de uma correlação entre três fatos simultâneos: a limitação do aproveitamento dos lotes urbanos, acarretando a expansão da área verticalizada, a desis- 
tência da construção do metrô e o desenvolvimento da indústria automobilistica. Isso sugere as caracteristicas definidas por Lipietz no estágio monopolista, onde ocorre uma rearticulação entre Estado, Mercado e Empresa, visando ao proveito ampliado na acumulação.

\section{O Quarto Período: A Influência do BNH - 1967/1972}

Em 1972, São Paulo contava com 17.112 elevadores instalados em 8.235 ediffcios. Desse conjunto, 2.201 foram construldos nesse perlodo de verticalizaçāo. Essa extraordinária ascensāo do crescimento vertical nesse perlodo, pode ser explicada pelo fato do BNH ter assumido, em 1967, a gestāo dos recursos do FGTS.

Por motivos de legitimação do governo revolucionário, bem como do estágio de mobilização das massas, os primeiros anos de atuação do BNH foram efetivamente voltados para o mercado popular. Do total de unidades financiadas no Brasil entre 1964 e 1969, $41 \%$ destinaram-se ao mercado popular (COHAB), $29 \%$ ao mercado econômico (cooperativas) e $30 \%$ ao mercado médio. No entanto, à medida que aumenta o fenômeno da inadimplência, o objetivo do Banco vai sendo substituldo. Entre 1970 e 1974, 63\% das unidades financiadas destinavam-se ao mercado médio, $25 \%$ ao mercado econômico e apenas $12 \%$ ao mercado popular. (Azevedo de Andrade, 1982, p. 91)

$O$ expediente utilizado pelos construtores de aprovar ediffcios residenciais como comerciais e com isso obter um C. A. de 6, passa a ser inviabilizado: o BNH so financiava habitações. Portanto, verifica-se nesse perlodo uma diminuiçāo efetiva do C. A, 6 para quatro vezes a área do terreno. Ocorre então uma nova expansão da área verticalizada, ainda que menos intensa que a decorrente da Lei n. 5.261. Por outro lado o BNH intensificou sobremaneira o fenômeno da verticalização uma vez que resolvia um dos problemas básicos do Setor Imobiliário que é a questão do financiamento.

\section{Quinto Período: A Influência do Zoneamento - 1972/1979}

A Lei do Zoneamento, promulgada em 1972, pontua a periodizaçāo do crescimento vertical de Sāo Paulo, constituindo-se uma nova limitação à possibilidade de multiplicar o solo urbano, dessa vez de maneira mais restrita e diferenciada. Essa nova limitação provoca uma expansão acentuada da nova área de verticalização, esta dirige-se para as áreas de preços fundiários menores. Em 1990, São Paulo contava com 39.757 elevadores instalados em 17.434 ediflcios.

A legișlação de zoneamento e sua aplicaçăo tem apresentado, nos seus quase vinte anos de existência, efeitos negativos no processo de produção da cidade.

A primeira crftica a ser feita ao zoneamento diz respeito à sua própria formulação. Baseada numa rede ortogonal de vias expressas, que não chegou a ser constitulda, os índices urbanísticos da lei de zoneamento não levaram em consideração a situação da infra-estrutura existente. Além disso, os índices não apresentam cor: elação alguma com a conformação física, a geomorfologia da cidade, uma vez que esta é tratada de forma bidimensional através de simples mapas.

Um efeito econômico perverso se traduz na supervalorização fundiária criada através da escassez de terra edificável. Só em $10 \%$ da cidade pode ser utilizado o coeficiente de aproveitamento de 4. Em 90\% da cidade pode-se construir até no máximo 2 vezes a área do terreno. $O$ zoneamento além de reforçar a diferenciação dos preços na cidade provoca uma formação artificial, na medida em que define aproveitamentos diferencia- 
dos. Além disso a segregação de zonas de uso reforça a formação de preços fundiários diferenciados. Uma área residencial "custa" menos do que uma área onde são permitidos usos comerciais ou de serviços, isto é, usos mais rentáveis.

A segregaçāo de usos na cidade, além de inflacionar os preços fundiários, reforça os problemas urbanos através da sobrecarga da infra-estrutura e do sistema viário. Regiōes estritamente residenciais nāo oferecem trabalhos, isto provoca o deslocamento da população para os centros de emprego sobrecarregando os transportes.

Os quase vinte anos da aplicação da lei de zoneamento tornaram-na um instrumento além de complexo, bastante complicado. Em 1972 foram criadas 8 zonas. Hoje existem 27 modalidades diferenciadas, consolidadas em leis que ocupam mais de 700 páginas de um compêndio. A falta de clareza da legislação é um dos fatores que reforça o processo de clandestinidade da cidade. Além de ser antidemocrática, uma vez que pode ser compreendida por poucos abre espaço para possiveis e prováveis desvios.

A clandestinidade também se multiplicou nas áreas onde o objetivo era a preservação ambiental. Áreas rurais e de proteção aos mananciais tiveram estabelecidos indices urbanisticos no sentido de se obter uma ocupação rarefeita. Os coeficientes de aproveitamento variam de 0,3 a 0,5 na zona rural e de proteção aos mananciais. Isto depreciou os preços da terra, fato que, aliado à pressão de uma demanda habitacional de baixa renda, redundou na proliferação de loteamentos irregulares. Esses loteamentos que abrigam uma parte da população de baixa renda, não atendem as exigências legais, estabelecendo padrōes de urbanização de baixissima qualidade ambiental.

A elevação dos preços da terra se compõe com um padrão extensivo de crescimento da cidade. Na medida em que a lei de zoneamento rebaixou e limitou os coeficientes de aproveitamento (antes de 1972 os CAs eram 6 e 4 para toda a cidade), houve aumento da demanda por terras, com conseqüente aumento de seus preços, além de ter exigido a extensão de serviços urbanos onerosos aos cofres públicos.

A crise econômica e o fim do BNH se manifestaram significativamente sobre a verticalizaçāo. A procura da solvabilidade e a falta de financiamentos restringiu o crescimento vertical a segmentos de alta renda. Ediffcios de alto luxo ou ainda flats caracterizaram a produçāo deste perlodo.

A pressāo do setor imobiliário para obter índices maiores do que o zoneamento permite resultou na aprovação da lei de desfavelamento, hoje chamada de Operaçōes Interligadas. Em síntese esta lei permite que derrogaçōes sejam aprovadas em troca de habitaçōes populares. Apesar de resultados ainda tímidos esta lei permite que se recupere socialmente parte da valorização imobiliária.

\section{Algumas Propostas do Plano Diretor}

Um primeiro pressuposto que norteou o processo de concepçāo e elaboração do P. D. constituiu-se no entendimento que a cidade é produzida por múltiplos agentes públicos e privados e que a ação do poder municipal (um dos agentes públicos), na efetividade de implementação de um plano, é limitada. O primeiro pressuposto portanto é que o P. D. consiste num conjunto de regras simples que articule a açāo dos agentes públicos e privados. Esse pressuposto foi decisivo no processo de elaboração do plano: as propostas foram construldas desde o início na discussão com os segmentos organizados da sociedade civil. Participaram dessa discussão desde agentes do capital, o setor imobiliário, comercial, industrial, até movimentos populares principalmente vinculados à demanda por habitaçāo (favelas, cortiços) e ainda, ecologistas e ambientalistas. Os agentes públicos que produzem a cidade também foram incorporados ao debate, 
vinculados a outras esferas do Poder Público: o Metrô, a Eletropaulo, a Sabesp, a Telesp, etc.

Um segundo pressuposo do Plano, face à constatação de que $67 \%$ da população da cidade vive em condiçōes precárias ou irregulares, consiste no seu caráter redistributivo. Incorporar a cidade real faz-se necessário, uma vez que $67 \%$ da população foram historicamente exclufdos dos planos e da legislaçāo vigente.

O terceiro pressuposto baseia-se no fato de que numa cidade de nove milhões de habitantes, torna-se impossivel o estabelecimento de regras e planos que atendam de forma global as suas diversidades e especificidades. O Plano Diretor abre a possibilidade de um planejamento em dois niveis: um mais geral e um detalhamento maior a ser desenvolvido em nivel local.

Uma caracterlstica que diferencia este plano dos anteriores é a sua auto-aplicabilidade. Os Planos Diretores anteriores se caracterizam por se constituirem numa Declaração dos Direitos do Cidadão e serem inefetivos do ponto de vista da transformaçāo da cidade. Hoje é a lei de zoneamento que dirige a construção da cidade formal. Abandonamos, portanto, a concepção de Plano Diretor inócuo visando sua maior efetividade nos destinos da cidade.

A estratégia geral do Plano consiste em ampliar a oferta de terra urbanizável e edificável. A ampliação da zona urbanizável será obtida através da revisão dos limites da zona rural. A ampliação da zona edificável (adensamento construído) será obtido através da definição de um coeficiente único, zonas nāo adensáveis e zonas adensáveis, onde existe folga de infra-estrutura. Nas zonas adensáveis a definição de um estoque de $\mathrm{m}^{2}$ edificáveis, que poderá ser consumido acima do coeficiente único mediante pagamento ao Poder Municipal, substitui a idéia de coeficientes de aproveitamento diferenciados por zona.

Um efeito esperado é a redução dos custos de urbanização através da racionalização da ocupação da cidade. O estabelecimento de zonas adensáveis e dos estoques de área construf́da foram determinados pela existência de infra-estrutura passivel de ser utilizada. Isto é: os estoques representam a quantidade de área construída que a infraestrutura e o viário suportariam hoje, sem nenhum investimento público.

Uma decorrência do estímulo ao adensamento qualificado proposto é uma reversão do processo de expansão da urbanização que demanda em extensão as redes de serviços urbanos. A diminuição do preço de venda do terreno ou seja da parcela que é apropriada pelo proprietário, deverá ocorrer através, de um lado, da estratégia de ampliação da oferta de terra e, por outro, da substituição do coeficiente de aproveitamento vinculado ao lote pelo estoque de área edificável. A definição de um coeficiente único na cidade deverá eliminar o diferencial que hoje existe nas zonas com usos e aproveitamentos diferenciados. $\mathrm{O}$ estoque de $\mathrm{m}^{2}$ de área edificável deverá ser outorgado onerosamente pelo Poder Municipal ao empreendedor que quiser ultrapassar o coeficiente único nas áreas adensáveis. Os recursos advindos dessa outorga onerosa constituirão um Fundo de Urbanização que servirá para a reposiçăo dos custos de adensamento. Note-se que o estoque desvinculado do lote evitará que o proprietário do terreno se aproprie do diferencial criado hoje artificialmente pelos coeficientes de aproveitamento diferenciados e estabelecidos pela lei atual.

É importante destacar que este instrumento, solo criado, reduzirá a apropriação de parte da valorização da terra, pelo proprietário do terreno, transferindo-a para o poder público municipal, constituindo o fundo de urbanização que será utilizado para a recuperação urbanística de parte da cidade precária e irregular. 


\section{Conclusões}

O que procuramos mostrar é que o crescimento vertical foi limitado pela legislação municipal através da diminuição crescente dos Coeficientes de Aproveitamento. Mostramos também de que forma ao longo dos períodos analisados, a verticalização passa de terciária a residencial e torna-se propriedade privada, fazendo com que o Estado cada vez mais se articule com o capital imobiliário, a ponto de definir, como vimos na lei de 1957. as classes que iriam habitar os ediffcios de apartamento. Isso nos faz concluir, de um lado, que a população de baixa renda foi excluída, pela legislação urbanistica, da possibilidade de acesso a essa mercadoria e, de outro, nos faz refletir a respeito das soluçōes possiveis para a habitação de baixa renda.

A limitação crescente do C. A. permitido favoreceu a supervalorização fundiária, uma vez que diminuiu a oferta de terra edificável, pressionando a demanda por terra urbana. $E$ isso de certa forma apresenta um obstáculo ao desenvolvimento da indústria da construção civil.

Constatamos também que a verticalização não ocorreu nas áreas com infra-estrutura e equipamentos. Prrtanto, conclulmos que um adensamento visando otimizar os investimentos já consolidados nas áreas urbanas é extremamente desejável e está intrinsecamente vinculado às propostas do novo Plano Diretor de São Paulo, que não só propōe também o aumento de área verticalizável, como também a recuperação de parte da valorização imobiliária produzida socialmente.

\section{Referências Bibliográficas}

AZEVEDO, Aroldo. A cidade de São Paulo, Associação dos Geógrafos, São Paulo, 1954. v. III.

AZEVEDO, Sérgio; ANDRADE, Luiz A. Gama de. Habitação e Poder, Rio de Janeiro, Zahar, 1982.

CAMPANÁRIO, Milton de Abreu. Land Rent ant the Reproduction of Labor force: some evidence from São Paulo, Tese apresentada na Comell University, 1981.

GRANELLE, Jean Jacques. Espace urbain et Prix du Sol, Paris, Sirey, 1970.

LIPIETZ, Alain. Le Capital et Son Espace, Maspero, Paris, 1977.

MARICATO, Ermínia (org.). A produção Capitalista da Casa (e da cidade) no Brasil Industrial. São Paulo, Alfa Ômega, 1982, 2ª ed.

ROLNIK, Raquel et alli. São Paulo Crise e Mudança, Brasiliense, 1990.

SILVA, L. A. M. da (org.). Solo urbano: Tópicos sobre o uso da terra, Rio de Janeiro, Zahar, Série Debates Urbanos, 1981.

SMOLKA, Martim O. Estruturas intra-urbanas e segregação social no espaço: elementos para uma discussão da cidude na Teoria Económica, Rio de Janeiro, PUR, 1983.

TOPALOV, Christian. Le profit, la rente et la ville, Paris, Econômica, 1984. 